\title{
Design a compact square ring patch antenna with AMC for SAR reduction in WBAN applications
}

\author{
Abdul Rashid O. Mumin, R. Alias, Jiwa Abdullah, Samsul Haimi Dahlan, Jawad Ali, \\ Sanjoy Kumar Debnath \\ Wireless Radio Science Centre (WARS) and Research Centre for Applied Electromagnetics, Faculty of Electrical \\ and Electronic Engineering, Universiti Tun Hussein Onn Malaysia, Johor, Malaysia
}

\begin{tabular}{l}
\hline \hline Article Info \\
\hline Article history: \\
Received Jul 21, 2019 \\
Revised Sep 26, 2019 \\
Accepted Dec 29, 2019 \\
\hline Keywords: \\
Artificial magnetic conductor \\
Defected ground structure \\
SAR reduction \\
Square ring antenna \\
Wireless body area network
\end{tabular}

\begin{abstract}
In this paper presents a compact square ring patch antenna with miniaturized AMC structure at $5.8 \mathrm{GHz}$ for WBAN applications. To minimize detuning, keeping its radiation efficiency high and acceptable gain while keeping the SAR levels low for safety is a challenging task. One of the critical issues in WBAN antenna design is the size of the antenna for portable devices, because the size affects the gain and bandwidth. The AMC configuration decreases the back radiation and the effect frequency detuning results from the high loss in the human body. Furthermore, the AMC also increases the front-to-back ratio (FBR) of $15.3 \mathrm{~dB}$. The proposed antenna has dimensions of $15.27 \times 15.27 \times 2.2 \mathrm{~mm}^{3}$ and provides a $404 \mathrm{MHz}$ impedance bandwidth, with a gain improvement of $8.69 \mathrm{dBi}$ and a $93.7 \%$ reduction of the initial SAR value. For this reason, the antenna is suitable for WBAN application in various fields, particularly in medical technology.
\end{abstract}

This is an open access article under the CC BY-SA license.

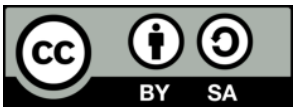

\section{Corresponding Author:}

Abdul Rashid O. Mumin,

Wireless Radio Science Centre (WARS),

Faculty of Electrical and Electronic Engineering,

Universiti Tun Hussein Onn Malaysia, Johor, Malaysia.

Email: Abdulrashidomar3@gmail.com

\section{INTRODUCTION}

Wireless body area network (WBAN) has attracted greater attention to providing the necessary communication needed for applications such as network applications, health monitoring, military and personal navigation entertainment [1-5]. However, the design of the WBAN antenna faces the biggest challenge in using the particles needed to fully understand the characteristics of the antenna and the loss of propagation in the existence of the human body [6]. For this reason, the importance of a high-efficiency antenna during body proximity becomes a necessity. In particular, the proximity of the body minimizes the efficiency of the antenna and maximizes radiation pattern irregularities and impedance detuning. Additionally, the impact of WBAN radiation on the human body is characterized by a specific absorption rate (SAR), which must be considered to avoid any effect on the human body, and the value must be a minimum [7]. Several types of antennas have been investigated such as a fully textile patch antenna and other structures of patch antennas [8-13], an inverted $F$ antenna planar [14-15], and antennas rela ted on integrated waveguides to the substrate, metamaterials are presented [16]. A planar waveguide fed slots and monopole antennas are demonstrated [7]. $61 \mathrm{GHz}$ Yagi-Uda antennas is presented for on-body communication [17]. Microstrip, planar and vertical monopole antennas were presented and their suitability as wearable antennas [18-24]. Alternatively, the electromagnetic bandgap structure (EBG) is included in the design of the antenna, which can be used to provide a high level of isolation from the human body 
and to reduce SAR in tissue. However, since most of the EBG-based designs are electrically large, the structure is still suffering high front-to-back ratio (FBR) with the cost of increased structural complexity [25]. AMC and DGS were proposed for gain enhancement [26-27].

In this paper, a miniature single-band antenna for WBAN at $5.8 \mathrm{GHz}$ is proposed. To achieve body performance adjusted easily and evenly at the same time a lower (SAR). In addition, the dimensions are $15.27 \times 15.27 \times 2.2 \mathrm{~mm}^{3}$, which demonstrate further size reduction compared to previously published studies. The preparation of this paper is described below II. The section introduces the antenna structure and developed multilayer human head tissue III. The comparison between the simulated and mea sured results are presented. Finally, the effect of the body on the performance of antenna and SAR value on hu m a h head are evaluated and draws the conclusion.

\section{ANTENNA DESIGN}

\subsection{Antenna geometry}

The structure of the demonstrated antenna is illustrated in Figure 1(a) and Figure 1(b). The presented antenna has a dimension of $L \times W$. Where $L$ and $W$ are the length and width of the resonance patch. This antenna is powered by a microstrip power supply having a characteristic impedance of $50 \mathrm{ohms}$. RT5880 substrate with permittivity of 2.2 with low tan loss of 0.0009 was used as substrate materials. This antenna was designed and simulated using a commercially available electromagnetic wave simulator CST Microwave Studio. Various substrates were used and evaluated in order to determine the performance of antenna and the effects of the different substrates of the proposed antenna. Table 1 summarizes the dimension of the proposed antenna while Table 2 shows the comparisons of the proposed antenna with other references.

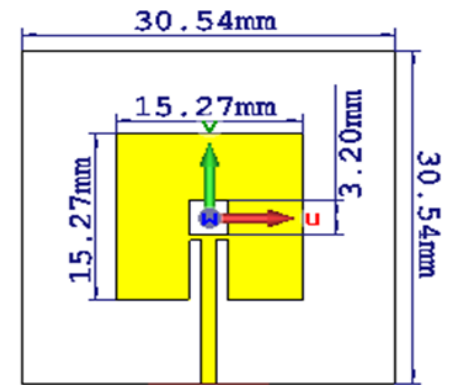

(a)

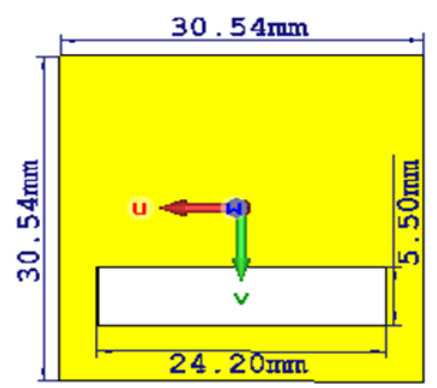

(b)

Figure 1. Geometry of the proposed antenna, (a) Front view, (b) Back view

Table 1. Dimensions of proposed antenna

\begin{tabular}{ccc}
\hline Parameters & RT5800 & FR4 \\
\hline Design frequency & $5.8 \mathrm{GHz}$ & $5.8 \mathrm{GHz}$ \\
Dimensions of patch & $\mathrm{L}=\mathrm{W}=15.27 \mathrm{~mm}$ & $\mathrm{~L}=\mathrm{W}=12.28 \mathrm{~mm}$ \\
Dielectric Constant & 2.2 & 4.3 \\
Tan $\delta$ & 0.0009 & 0.025 \\
Height & 1.57 & 1.6 \\
slot & $3.20 \mathrm{~mm}$ & $3.20 \mathrm{~mm}$ \\
Lf & $13.40 \mathrm{~mm}$ & $9.43 \mathrm{~mm}$ \\
\hline
\end{tabular}

Table 2. Comparison of gain, radiation, and sar of the proposed antenna with other references

\begin{tabular}{cccc}
\hline Reference & Gain & Radiation efficiency & Reduced SAR \\
\hline 21 & 5.9 & 35.7 & $70 \%$ \\
22 & 7.1 & N/A & $58.5 \%$ \\
23 & 9.6 & $46.3 \%$ & $80 \%$ \\
10 & 0 & $76 \%$ & $47 \%$ \\
Proposed & 8.69 & $95 \%$ & $90 \%$ \\
\hline
\end{tabular}

In order to achieve the desired resonant frequency, the following mathematical approach is applied [20].

$$
L o=W_{0}=0.46 \frac{\lambda}{\sqrt{\varepsilon r}}
$$




\subsection{AMC structure}

The $2 \times 3$ AMC current plays an important role in reducing the proposed antenna profile and is placed under the emitted element as the PEC ground. The geometry of the AMC is shown in Figure 2. RT5880 substrate with permittivity of 2.2 with low tan loss of 0.0009 with thickness $1.57 \mathrm{~mm}$ was used the proposed AMC as substrate materials as shown in Figure 2. The useful bandwidth of an AMC is in general defined as $+90^{\circ}$ to $-90^{\circ}$ on either side of the central frequency $\left(+90^{\circ}\right.$ to $\left.-90^{\circ}\right)$ on either side of the central frequency. As shown in Figure 3, use the multi-layer human head model to determine antenna performance in human body scenarios. The multilayer human phantom constructed with five layers of tissues based electromagnetic properties and these tissues represent parts of the human head such as skin, fat, cerebrospinal fluid, bone, and brain. The thickness and electrical properties at $5.8 \mathrm{GHz}$ are listed in Table 3 .
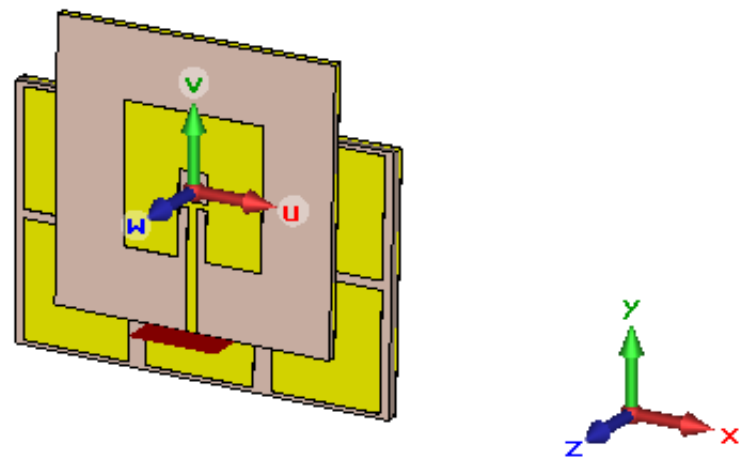

Figure 2. The geometry of the AMC unit with proposed antenna

Table 3. Dielectric properties of biological tissues used human head at $5.8 \mathrm{GHz}$

\begin{tabular}{cccc}
\hline Tissues & Relative Permittivity $(\mathrm{er})$ & Tan $\delta$ & Thickness $\left(\mathrm{mm}^{2}\right)$ \\
\hline Skin & 35.11 & 0.33 & 2 \\
Fat & 9.86 & 0.26 & 2 \\
Bone & 60.47 & 0.37 & 7 \\
CSF & 60.47 & 0.40 & 1 \\
Brain & 44.00 & 0.35 & 35 \\
\hline
\end{tabular}

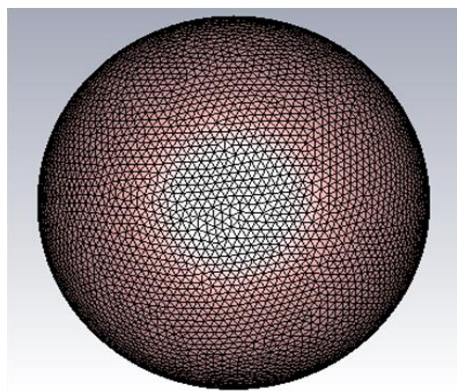

(a)

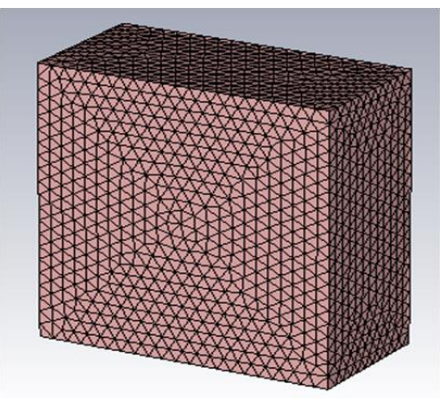

(b)

Figure 3. Proposed phantom models of human head, (a) Spherical phantom, (b) Cubical phantom

\section{RESULTS AND DISCUSSION}

The use of a single-band antenna is proposed and some important parameters should be carefully considered. The simulation results show that the antenna performance strongly influenced on the dimensions, the short pins, and the AMC reflectors. The structure of AMC unit was demonstrated the reflection characteristics of proposed AMC reflector as shown in Figure 2. The AMC surface resonance frequency corresponds to a degree of reflection coefficient to the $0^{\circ}$. The AMC reflection phase bandwidth is described by a phase range between $-90^{\circ}$ to $90^{\circ}$. Hence the dimension of the AMC, Ls is varied to obtain resonance at the desired frequency. The reflection phase varies from $150^{\circ}$ to $-150^{\circ}$ at resonance, which is at $5.8 \mathrm{GHz}$, 
the reflection phase is $0^{\circ}$ the frequency is laid $5.79 \mathrm{GHz}$. Furthermore, the rectangular patch AMC has a reflection magnitude of $-0.129 \mathrm{~dB}$. The key parameter used to control the phase shift is the length of patch. Moreover, increasing or decreasing the lengths causes the fundamental resonance frequency to shift to high er or low frequencies. This type of unit cell offers simple and less fa brication complexity technique: Reflection phase with varying dimensions for the proposed AMC structure is shown in Figure 4.

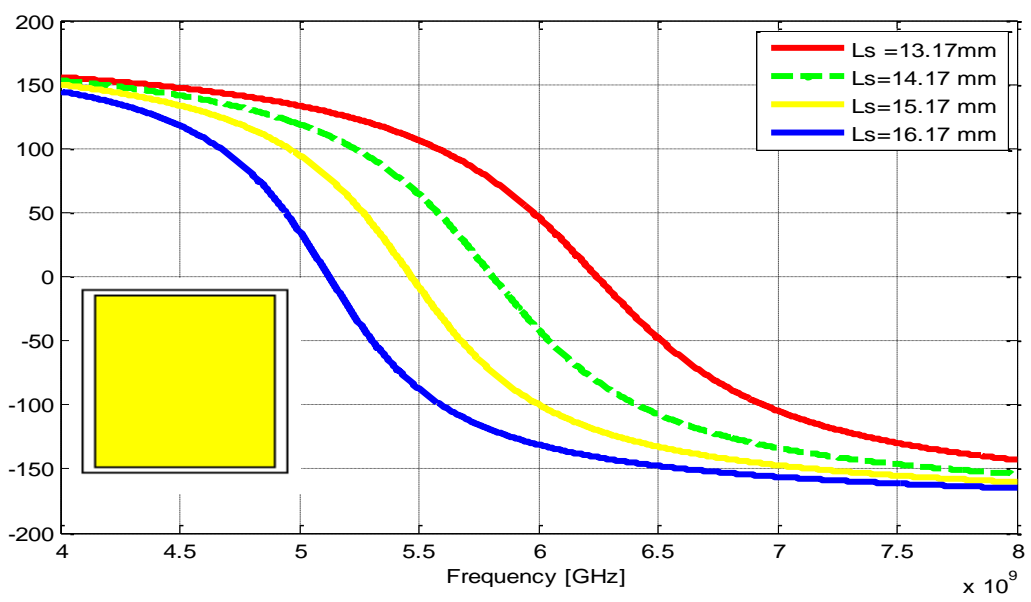

Figure 4. Simulated reflecting phases of the AMC unit

In the previous section, patch antenna designs with $\mathrm{AMC}$ covering $5.8 \mathrm{GHz}$ is proposed, to compare the antenna performance various configurations of AMC were performed. Furthermore, the a ntenna performance enhanced by applying AMC and this signifies that the structure has a better effect for resonance frequency compared for the rest AMC structure which has been presented in previous works. As increasing AMC case with three to five columns, the structure will have a larger size and lower improvement. The simulated S-parameter was shifted after using 5-column with a good matching S-parameter of less than-10 dB. As shown in Figure 5, the simulated s-parameter for antenna without using AMC pointed at $5.8 \mathrm{GHz}$ with matching $\mathrm{S}_{11}$ equal to $-22.72 \mathrm{~dB}$.

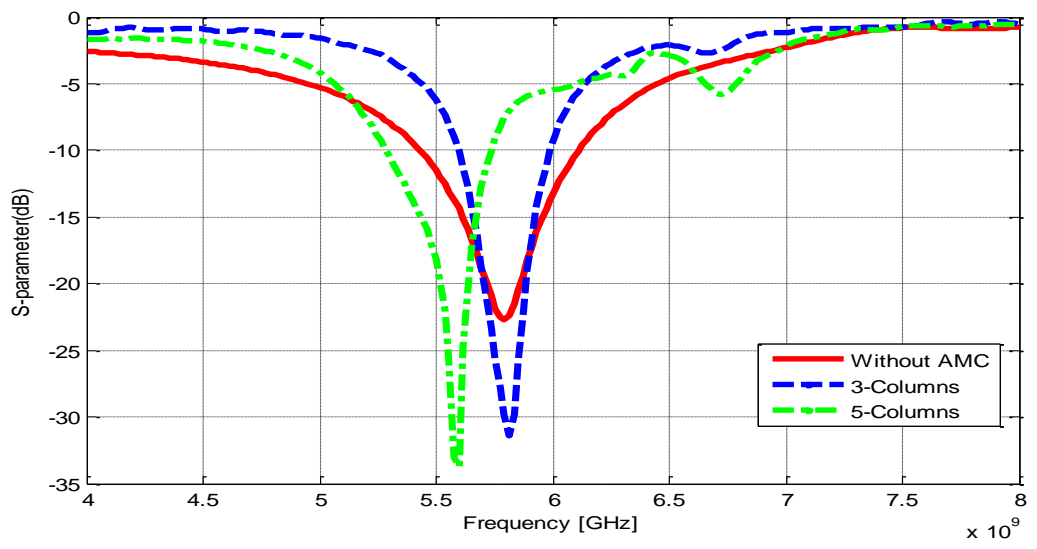

Figure 5. Comparison reflection curves without and with AMC structure

As shown in Figure 6, the simulated and measured results of S-parameters. Therefore, the comparison between the simulated and measured impedance bandwidths are $608.9 \mathrm{MHz}$ and $404 \mathrm{MHz}$ respectively. VSWR is falling below 2. The simulated and measured s-parameters of the proposed antenna in free space with and without the AMC structure are compared as shown in Figure 6. The operation of the optimized AMC layer is considered wider than the $\mathrm{S}_{11}<-10 \mathrm{~dB}$ and bandwidth of conventional square slot. As shown in Figure 7 and Figure 8, the simulated and measured radiation pattern of the demonstrated antenna. The measured gain of the demonstrated antenna is around

Design a compact square ring patch antenna with AMC for SAR reduction in ... (Abdul Rashid O. Mumin) 
$8.67 \mathrm{dBi}$. The comparison between the simulated and mea sured radiation pattern indicated a good agreement. Therefore, there are slight differences between the simulated and measured which is attributed to fabrication error and soldering.

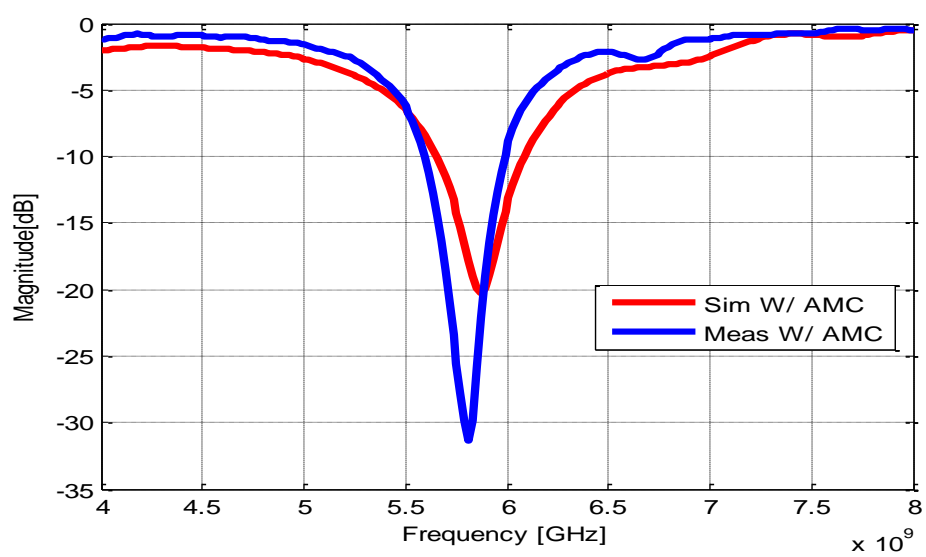

Figure 6. Comparison simulated $s$-para meters with AMC structure
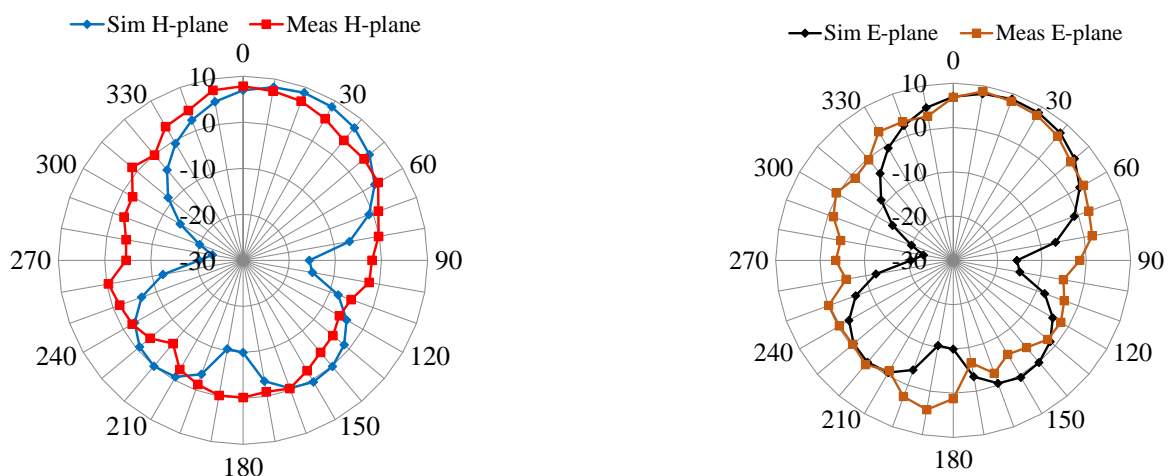

Figure 7. The comparison between simulated measured E-Plane and H-Plane radiation patterns with DGS at $5.8 \mathrm{GHz}$ using RT 5880 substrate
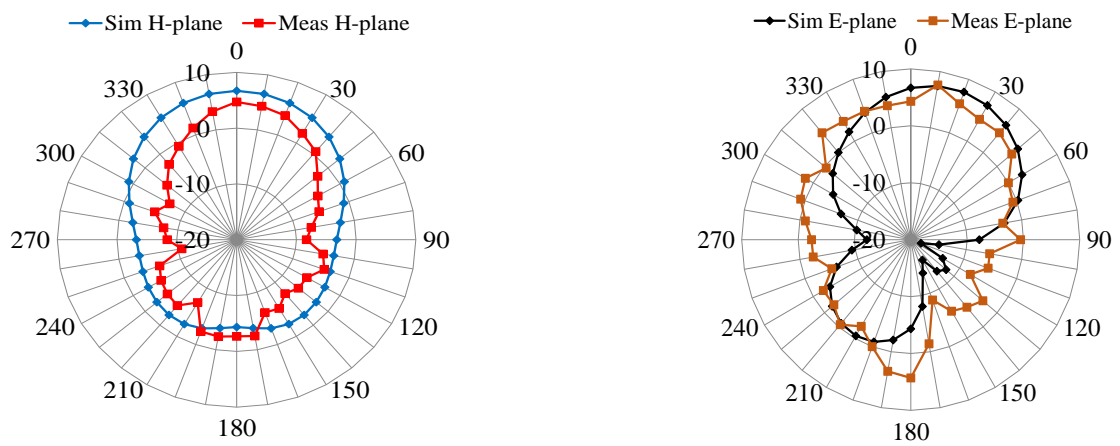

Figure 8. The comparison between simulated and mea sured E-Plane and H-Plane radiation patterns with AMC at $5.8 \mathrm{GHz}$ using RT 5880 substrate

\subsection{Investigation of specific absorption rate (SAR) in human head}

In this section is discussed the effect of body on the antenna performance and SAR value on hu m a $n$ head, when the human head experience higher frequency exposure of $5.8 \mathrm{GHz}$ from a portable device. The various substrate of patch antenna also influences the SAR of a human head. Figure 9 exhibits the comparison scattering parameter $\left(\mathrm{S}_{11}\right)$ at $5.8 \mathrm{GHz}$ frequency after the placement of an electromagnetic 
AMC reflector. The placement of the absorber in between the microstrip antenna and the bio -tissue offers significant improvement and reduction SAR. The shift of the antenna resonant frequency is mainly due to the high permittivity characteristic and the shape of the phantom head model. The simulated impedance bandwidth in with AMC as $396 \mathrm{MHz}(5.6 \mathrm{GHz}-5.99 \mathrm{GHz})$, as $472 \mathrm{MHz}(5.62 \mathrm{GHz}-6.12 \mathrm{GHz})$ and as 419 $\mathrm{MHz}(5.63 \mathrm{GHz}-6.1 \mathrm{GHz})$ as shown in Figure 9. Furthermore, the simulated $\mathrm{S}_{11}$ is below $-10 \mathrm{~dB}$ with the magnitude of $S_{11}-31.39 \mathrm{~dB}$ while the cubical and spherical phantom with the magnitude of $\mathrm{S}_{11}-16.53 \mathrm{~dB}$ and $-16.48 \mathrm{~dB}$ respectively. The numerical result of the antenna performance and the SAR value due to the patch antenna placed in proximity to the different types of phantom head models are presented in this section. two different types of phantom head models including cubical phantom, sphericalphantom are used for estimating the antenna performance and the SAR value is investigated further studies on the effects of two different types phantom head models are analyzed. The effects of the antenna performance and the SAR value of the patch antenna with the phantom head models are also included. The simulated results of the antenna performance including return loss are discussed. The maximum local averaged SAR over $10 \mathrm{~g}$ of tissue and SAR distribution on the phantom head is also analyzed.

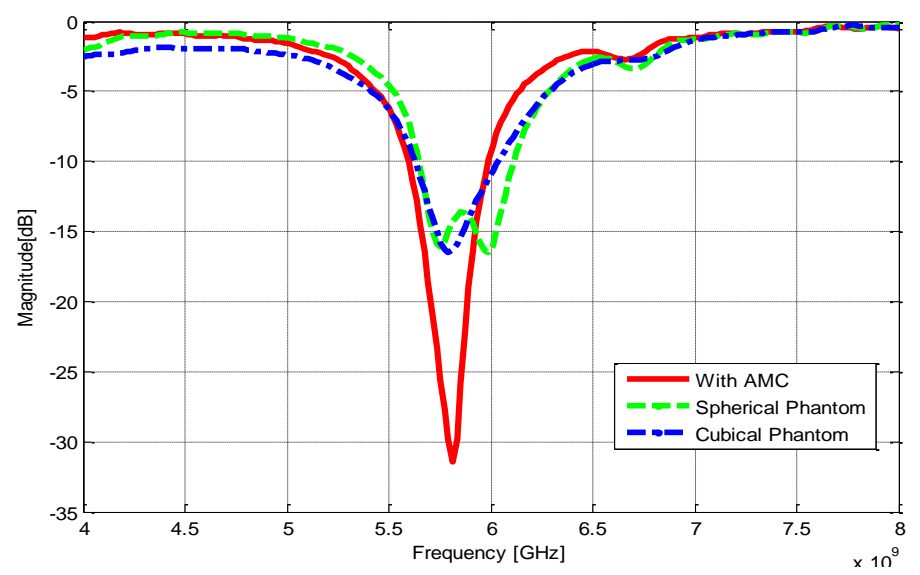

Figure 9. Simulated s-parameters with and without AMC reflector structure on human head phantom

Overall, the simulated SAR at $5.8 \mathrm{GHz}$ distributed on the human head surface is much higher than the maximum limit defined by ICNIRP averaged over $10 \mathrm{~g}$ of any tissue which should be less than $2 \mathrm{~W} / \mathrm{Kg}$. The proposed antenna was placed on the human head phantom in order to perform SAR evaluation. The initial results indicated that simulated SAR value is higher than the maximum limit, In order to reduce SAR value, AMC is used. At this frequency exposure, a square antenna with a substrate of RT-5880 substrate with spherical phantom has the highest SAR value $5.66 \mathrm{~W} / \mathrm{Kg}$, while antenna with AMC contributed the lowest SAR value of 0.353 for $10 \mathrm{~g}$ tissue at $5.8 \mathrm{GHz}$ frequency exposed. Figure 10 shows the SAR distribution of the phantom head models.
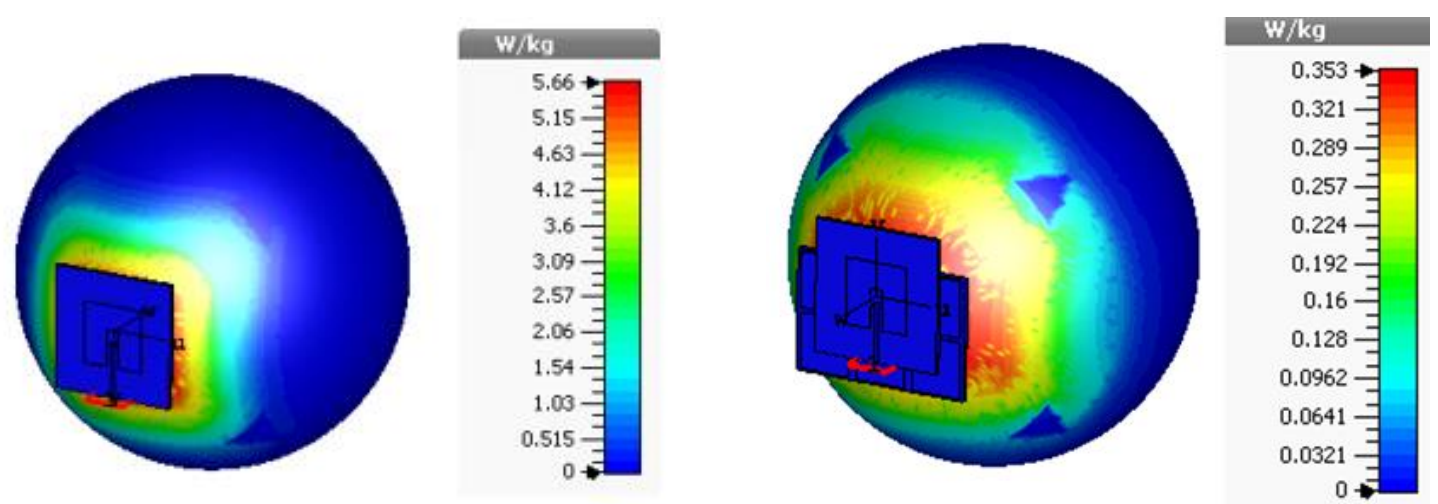

Figure 10. Simulated SAR value on a spherical phantom with and without AMC reflector structure on human head phantom 


\section{CONCLUSION}

The main purpose of this research was to investigate the main factors that degrade the perform ance of antenna after placing in the vicinity of the human body. Then design antennas to avoid or minimize the effect of those factors. Square ring patch antenna with compact AMC structure for wireless body area network application was successfully designed, simulated and measured. The AMC structure and minia turized reflector reduce the back radiation and the impact of frequency detuning due to high losses of the human body and the two proposed techniques are mounted on a human head phantom. In addition, AMC improved the front-to-back ratio (FBR) by $15.3 \mathrm{~dB}$ with enhanced gain $8.69 \mathrm{dBi}$ and radiation efficiency more than $80 \%$. The AMC has achieved a $93.7 \%$ reduction of the initial SAR.

\section{ACKNOWLEDGEMENTS}

The authors would like to thank (ORICC) UTHM fellowship Grant Vote U585. This paper was partly sponsored by the Research Management Centre (RMC) UTHM.

\section{REFERENCES}

[1] O. M. Khan, Q. U. Islam, R. M. Shubair and A. Kiourti, "Novel multiband flamenco fractal antenna for wearable WBAN off-body communication applications," 2018 International Applied Computational Electromagnetics Society Symposium (ACES), Denver, CO, pp. 1-2, 2018.

[2] J. Tak, S. Woo, J. Kwon and J. Choi, "Dual-band dual-mode patch antenna for on-/off-body WBAN communications," in IEEE Antennas and Wireless Propagation Letters, vol. 15, pp. 348-351, 2016.

[3] X. Y. Zhang, H. Wong, T. Mo and Y. F. Cao, "Dual-band dual-mode button antenna for on-body and off-body communications," in IEEE Transactions on Biomedical Circuits and Systems, vol. 11, no. 4, pp. 933-941, Aug. 2017.

[4] X. Tong, C. Liu, X. Liu, H. Guo and X. Yang, "Switchable on-/off-body antenna for $2.45 \mathrm{GHz}$ WBAN applications," in IEEE Transactions on Antennas and Propagation, vol. 66, no. 2, pp. 967-971, Feb. 2018.

[5] S. Kang and C. W. Jung, "Wearable fabric reconfigurable beam steering antenna for on/off-body communication system," 015 IEEE International Symposium on Antennas and Propagation \& USNC/URSI National Radio Science Meeting, Vancouver, BC, pp. 1211-1212, 2015.

[6] A. Kumar, A. Utsav and R. K. Badhai, "A novel copper-tape wideband wearable textile antenna for WBAN applications," 2017 IEEE Applied Electromagnetics Conference (AEMC), Aurangabad, pp. 1-3, 2017.

[7] Ashap, Adel Y. I., Z. Z. Abidin, S. H. Dahlan, H. A. Majid, S. K. Yee, Gameel Saleh, and Norun Abdul Malek. "Flexible wearable antenna on electromagnetic band gap using PDMS substrate." Telecommunication, Computing, Electronics and Control (TELKOMNIKA), vol. 15, no. 3, pp. 1454-1460, September 2017.

[8] Abdulhameed, M. K., Isa, M. M., Zakaria, Z., Ibrahim, I. M., \& Mohsin, M. K., "Radiation pattern control of microstrip antenna in elevation and azimuth planes using EBG and pin diode," in International Journal of Electrical and Computer Engineering (IJECE), vol. 9, no. 1, pp. 332-340, Febuary 2019.

[9] Razali, Nurul Inshirah Mohd, Norhudah Seman, and Nur Ilham Aliyaa Ishak, "Design and specific absorption rate of $2.6 \mathrm{GHz}$ rectangular-shaped planar inverted-F antenna," in Indonesian Journal of Electrical Engineering and Computer Science (IJEECS), vol. 10, no. 2, pp. 741-747, May 2018.

[10] T. Björninen and F. Yang, "Low-profile head-worn antenna with a monopole-like radiation pattern," in IEEE Antennas and Wireless Propagation Letters, vol. 15, pp. 794-797, 2016.

[11] D. Colombi, B. Thors and C. Törnevik, "Implications of EMF exposure limits on output power levels for 5G devices above $6 \mathrm{GHz}$," in IEEE Antennas and Wireless Propagation Letters, vol. 14, pp. 1247-1249, 2015.

[12] N. Chahat, M. Zhadobov, and R. Sauleau, "Antennas for body centric wireless communications at millimeter wave frequencies," in Progress in Compact Antennas, Rijeka, Croatia: InTech., 2014.

[13] P. B. Samal, P. J. Soh and G. A. E. Vandenbosch, "UWB all-textile antenna with full ground plane for off-body WBAN communications," in IEEE Transactions on Antennas and Propagation, vol. 62, no. 1, pp. 102-108, Jan. 2014.

[14] S J. Chen, T. Kaufmann, and C. Fumeaux, "Shorting strategies for a wearable L-slot planar inverted-F antenna," 2014 International Workshop on Antenna Technology: Small Antennas, Novel EM Structures and Materials, and Applications (iWAT), Sydney, NSW, pp. 18-21, 2014.

[15] P. J. Soh, G. A. E. Vandenbosch, S. L. Ooi and N. H. M. Rais, "Design of a broadband all-textile slotted PIFA," in IEEE Transactions on Antennas and Propagation, vol. 60, no. 1, pp. 379-384, Jan. 2012.

[16] S. Agneessens, S. Lemey, T. Vervust and H. Rogier, "Wearable, small, and robust: the circular quarter-mode textile antenna," in IEEE Antennas and Wireless Propagation Letters, vol. 14, pp. 1482-1485, 2015.

[17] C. Leduc and M. Zhadobov, "Impact of antenna topology and feeding technique on coupling with human body: application to 60-GHz antenna arrays," in IEEE Transactions on Antennas and Propagation, vol. 65, no. 12, pp. 6779-6787, Dec. 2017.

[18] M. L. Scarpello, L. Vallozzi, H. Rogier, and D. Vande Ginste, "Highgain textile antenna array system for off-body communication," in International Journal of Antennas and Propagation, vol. 2012, no. 4, January 2012. 
[19] S. Kang and C. W. Jung, "Wearable fabric reconfigurable beam-steering antenna for on/off-body communication system," 2015 IEEE International Symposium on Antennas and Propagation \& USNC/URSI National Radio Science Meeting, Vancouver, BC, pp. 1211-1212, 2015.

[20] A. O. Mumin, R. Alias, A. A. Awaleh and R. A. Abdulhasan, "Assessment of microstrip patch antenna performance based on dielectric substrate," 2015 International Conference on Computer, Communications, and Control Technology (I4CT), Kuching, pp. 468-471, 2015.

[21] M. Wang et al., "Investigation of SAR reduction using flexible antenna with metamaterial structure in wireless body area network," in IEEE Transactions on Antennas and Propagation, vol. 66, no. 6, pp. 3076-3086, June 2018.

[22] N. A. Elias, N. A. Samsuri, M. K. A. Rahim, N. Othman and M. E. Jalil, "Effects of human body and antenna orientation on dipole textile antenna performance and SAR," 2012 IEEE Asia-Pacific Conference on Applied Electromagnetics (APACE), Melaka, pp. 132-136, 2012.

[23] W. Lei, H. Chu and Y. Guo, "Design of a circularly polarized ground radiation antenna for biomedical applications," in IEEE Transactions on Antennas and Propagation, vol. 64, no. 6, pp. 2535-2540, June 2016.

[24] Mumi, A. R. O., Alias, R., Abdullah, J., Dahlan, S. H., \& Ali, J., "Assessment of electromagnetic absorption towards human head using specific absorption rate," Bulletin of Electrical Engineering and Informatics (BEEI), vol. 7, no. 4, pp. 657-664, December 2018.

[25] Abdulhameed, M. K., Isa, M. M., Zakaria, Z., Mohsin, M. K., \& Attiah, M. L., "Mushroom-Like EBG to Improve Patch Antenna Performance For C-Band Satellite Application," International Journal of Electrical and Computer Engineering (IJECE), vol. 8, no. 5, pp. 3875-3881, October 2018.

[26] Bahari, N., Jamlos, M. F., \& Isa, M. M., "Gain enhancement of microstrip patch antenna using artificial magnetic conductor," Bulletin of Electrical Engineering and Informatics (BEEI), vol. 8, no. 1, pp. 166-171, March 2019.

[27] Islam, M. S., Ibrahimy, M. I., Motakabber, S. M. A., Hossain, A. Z., \& Azam, S. K., "Microstrip patch antenna with defected ground structure for biomedical application," Bulletin of Electrical Engineering and Informatics (BEEI), vol. 8, no. 2, pp. 586-595, June 2019.

\section{BIOGRAPHIES OF AUTHORS}

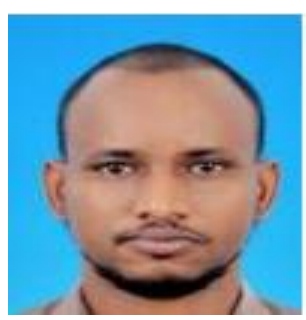

Abdul Rashid Omar Mumin received a BEng degree (with honors) in Electrical and Electronic Engineering from Universiti Tun Hussein Onn Malaysia (UTHM) in 2013, the MSc degree in Electrical Engineering from Universiti Tun Hussein Onn Malaysia (UTHM) in 2015 and PhD degree in Electrical and Electronic Engineering, Universiti Tun Hussein Onn Malaysia (UTHM) in 2019. His research interests include antenna design, microwave devices and reduction SAR for WBAN antennas.

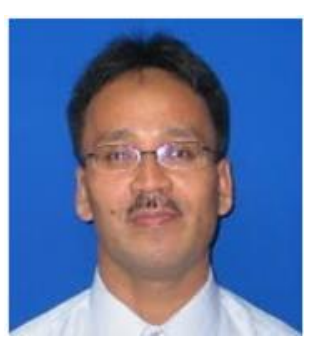

Rozlan Alias He received a BEng degree (with honors) in Electrical Engineering from the University of Malaya, Kuala Lumpur in 1991, a MSc degree in Digital Communication Systems from the University of Loughborough, UK in 1998, and a $\mathrm{PhD}$ degree in Electronics and Telecommunication from the University of Bradford, UK in 2006. He held the lecturing position at Universiti Kuala Lumpur (UniKL BMI), Gombak, Selangor for several years. He is currently an Associate Professor with the faculty of electrical and electronic engineering (UTHM) Parit Raja, Batu Pahat, and Johor, Malaysia. His research interests cover the hybrid electromagnetic computational techniques, antenna design and low SAR antennas for mobile handset.

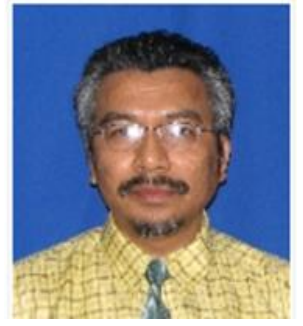

Jiwa Abdullah received B.Eng (Hons) Electronic Eng (Liverpool, UK) 1983 Edu. Cert. (MPPP) 1984 M.Sc Digital Communication System (Lboro, UK) 1990 PhD Electrical and Electronic Eng (Lboro, UK) July 2008. He is currently an Associate Professor with the faculty of electrical and electronic engineering (UTHM). Parit Raja, Batu Pahat, Johor, Malaysia. His research interests cover. Mobile Ad Hoc Networks Wireless Sensor networks Vehicular Ad Hoc Network Mobile and Wireless Communication Maritime Communication Spectrum Management Cognitive Radio Computer Networks/Broadband Networks Electrical Eng Education. 

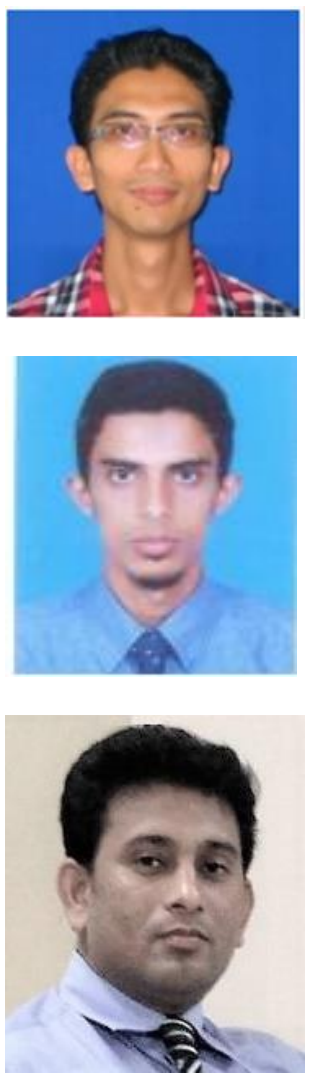

Samsul Haimi Dahlan received the Degree in Electrical Engineering from the Universiti Kebangsaan Malaysia in 1999, Master's Degree in Electrical and Electronic Engineering from the Universiti Teknologi Malaysia in 2005, and the Ph.D Degree in Signal Processing and Telecommunications from the Universite de Rennes I, France in 2012. He is currently an Associate Professor with the faculty of electrical and electronic engineering (UTHM). Parit Raja, Batu Pahat, Johor, Malaysia. His research interests cover. Microwave devices, numerical method (FDTD), antenna design and EBG.

Jawad Ali received B.Eng. (Hons.) Electrical Engineering degree from The University of Lancaster, UK in 2014. Thereafter, he joined Radio Communications and Antenna Design (RACAD) laboratory, where he completed his M.Eng. Degree by research at Universiti Tun Hussein Onn Malaysia (UTHM), Johor, Malaysia in 2018. He Joined Electrical Engineering Department, COMSATS University Islamabad (CUI), Lahore Campus, Pakistan in 2015, where he was associated with the cluster of Antenna and Radar Research Group. His research interests include dielectric based material study, antenna designing, radar study, electromagnetic engineering, and dual band transceiver.

Sanjoy Kumar Debnath is a PhD scholar in the Universiti Tun Hussein Onn Malaysia (UTHM) under the Faculty of Electrical \& Electronic Engineering. He received his Master of Engineering in Electrical Mechatronics and Automatic Control from Universiti Teknologi Malaysia (UTM) in 2014 and Bachelor of Science in Electrical and Computer Engineering in 2008 from Presidency University, Dhaka, Bangladesh. His research topic is on "Unmanned Air Vehicle. 